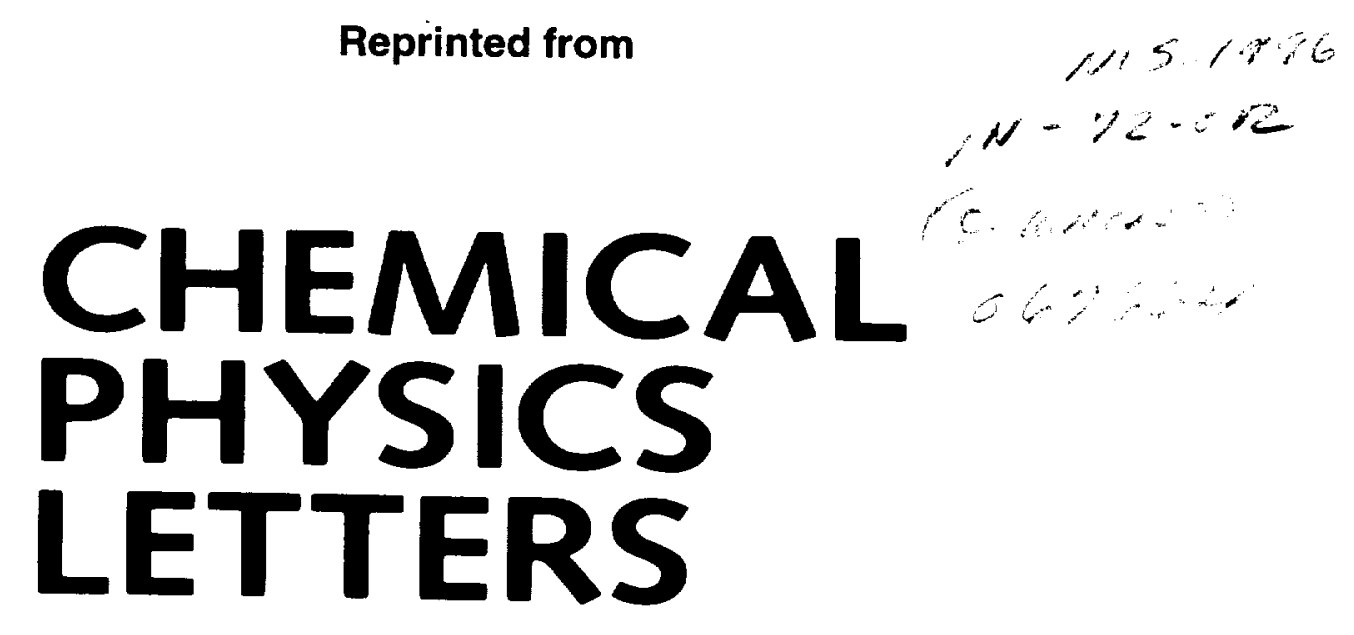

\title{
Electron-ion recombination rate coefficient measurements in a flowing afterglow plasma
}

Theodosia Gougousi ${ }^{a}$, Michael F. Golde ${ }^{b}$, Rainer Johnsen ${ }^{a}$

' Department of Physics and Astronomy, University of Pitrsburgh, Pittsburgh, PA 15260, USA

'Department of Chemistry. University of Pittsburgh, Pitssburgh, PA 15260. USA

Received 22 November 1996

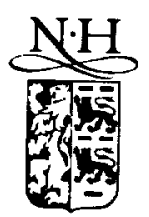

ELSEVIER 
EDITORS: A.D. BUCKINGHAM. D.A. KING. A.H, ZEWAIL Assistant Editor: Dr. R. Kobayashi, Cambridge, UK
FOUNDING FDITORS: G J HOYTINK L JANSEN

FORMER EDITORS: R.B. BERNSTEIN, D.A. SHIRLEY, R.N. ZARE

\section{ADVISORY EDITORIAL BOARD}

Australia

B.J. ORR, Sydney

Cunoda

P.A. HACKETT, Ottawa

J.W. HEPBURN, Waterloo

C.A. McDOWELL, Vancouver

Ciech Republic

Z. HERMAN, Prague

Denmark

F. BESENBACHER, Aarhus

G.D. BILLING, Copenhagen

France

E. CLEMENTI. Strasbourg

J. DURUP, Toulouse

J.-M. LEHN. Strasbourg

J.-L. MARTIN, Palaiseau

B. SOEP, OTsay

Germany

R. AHLRICHS, Karlsruhe

V.E. BONDYBEY, Garching

W. DOMCKE. Dusseldorf

G. ERTL. Berlin

G. GERBER, Würzburg

G.L. HOFACKER, Garching

D.M. KOLB, UIm

J. MANZ, Berlin

M. PARRINELLO, Stutigan

S.D. PEYERIMHOFF, Bon

R. SCHINKE, Gottingen

E.W. SCHLAG, Garching

J. TROE, Gortingen

H.C. WOLF, Stuttgart

W. ZINTH, Munich

India

C.N.R. RAO, Bangalore

Israel

J. JORTNER, Tel Aviv

R.D. LEVINE, Jerusalem lialy

V. AQUILANTI, Perugia

Japan

H. HAMAGUCHI, Tokyo

M. ГTO, Okazaki

T. KOBAYASHI, Tokyo

K. KUCHITSU, Sakado

H. NAKATSUH, Kyolo

K. TANAKA, Tokyo

K. YOSHIHARA, Okazaki

People's Republic of China

C.-H. ZHANG, Beijing

Poland

Z.R. GRABOWSKI, Warsaw

Russian Federation

A.L. BUCHACHENKO, Moscow

V.S. LETOKHOV, Troitzk

Yu.N. MOLIN, Novosibirsk

Spain

A. GONZÁLEZ UREÑA, Madrid

Sweden

P.E.M. SIEGBAHN, Stockholm

$\checkmark$. SUNDSTRŌM, Lund

Switzerland

M. CHERGUI, Lausanne-Dorigny

R.R. ERNST, Zurich

M. QUACK, Zurich

Taiwan, ROC

Y.T. LEE, Taipei

The Netherlands

A.J. HOFF, Leiden

A.W. KLEYN, Amsterdam

D.A. WIERSMA, Groningen

United Kingdom

M.N.R. ASHFOLD, Bristol

G.S. BEDDARD, Leeds

M.S. CHILD, Ox ford
D.C. CLARY, London

R. FREEMAN, Cambridge

R.H. FRIEND, Cambridge

N.C. HANDY, Cambridge

A.C. LEGON, Exeter

R.M. LYNDEN-BELL, Belfası

J.P. SIMONS, Ox ford

I.W.M. SMITH, Birmingham

USA

P. A VOURIS, Yorktown Heights, NY

A.J. BARD, Austin, TX

A.W. CASTLEMAN Jr., University Park, PA

S.T. CEYER, Cambridge, MA

D. CHANDLER, Berkeley, CA

F.F. CRIM, Madison, WI

A. DALGARNO, Cambridge, MA

C.E. DYKSTRA, Indianapolis, IN

K.B. EISENTHAL, New York, NY

M.A. EL-SAYED, Atlanta, GA

M.D. FA YER, Stanford, CA

G.R. FLEMING, Chicago, IL

R.M. HOCHSTRASSER, Philadelphia, PA

J.L. KINSEY, Houston, TX

S R IEONE, Boulder, CO

M.I. LESTER, Philadephia, PA

W.C. LINEBERGER, Boulder, CO

B.V. McKOY, Pasadena, CA

W.H. MILLER, Berkeley, CA

K. MOROKUMA. Atlanta, GA

S. MUKAMEL, Rochester, NY

A. PINES, Berkeley, CA

A.R. RAVISHANKARA, Boulder, CO

S.A. RICE, Chicago, IL

P.J. ROSSKY, Austin, TX

R.J. SAYKALLY, Berkeley. CA

H.F. SCHAEFER III, Athens, GA

G.C. SCHATZ, Evanston, It

R.E. SMALLEY, Houston, TX

W C STWALLEY, StorTs, CT

D.G. TRUHLAR, Minneapolis, MN

J.J. VALENTINI, New York, NY

G.M. WHITESIDES, Cambridge, MA

C. WITTTG, Los Angeles, CA

P.G. WOLYNES, Urbana, IL

JT YATES Jr., Pittsburgh, PA

R.N. ZARE, Stanford, CA

Contributions should, preferably, be sent to a member of the Advisory Editorial Board (addresses are given in the first issue of each volume) who is familiar with the research reported, or to one of the Editors:

A.D. BUCKINGHAM
D.A. KING
Editor of Chemical Physics Letters
University Chemical Laboratory
Lensfield Road
Cambridge CB2 IEW, UK
FAX 44-1223-336362

A.H. ZEWALL

Editor of Chemical Physics Letters

A.A. Noyes Laboratory of Chemical Physics

Califomia Institute of Technology

Mail Code 127.72

Pasadena, CA 91125 , USA

FAX 1-818-4050454

After acceptance of the paper for publication, all further correspondence should be sent to the publishers (Ms. S.A. Hallink, Issue Management (Chemistry), Elsevier Science B.V., P.O. Box 2759, 1000 CT Amsterdam. The Netherlands; telephone 31-20-4852664, FAX 31-20-4852775, telex 10704 espom nl; electronic mail X400: C-NL; A=400NET; P-SURF; O-ELSEVIER; S-HALLINK, I-S or RFC822: S. HALLINK@ELSEVIER.NL).

Publication information: Chemical Physics Letters (ISSN 0009-2614). For 1997, volumes 264-280 are scheduled for publication. Subscription prices are available upon request from the publisher. Subscriptions are accepted on a prepaid basis only and are entered on a calendar year basis. Issues are sent by surface mail able upon request from the publisher. Subscriptions are accepted on a prepaid basis only and are entered on a calendia, Brazil, Canada, Hong Kong, India, Israel, Japan, Malaysia. except to the following count PR China, Singapore, South Africa, South Korea, Tawan, Thailand, USA. For all other countries airmail rates are available upon request. Claims for missing issues must be made within six months of our publication (mailing) date.

Copyright 0 1997, Elsevier Science B.V. All rights reserved

$0009-2614 / 1997 / \$ 17.00$

US mailing notice - Chemical Physics Letters (ISSN 0009-2614) is published weekly by Elsevier Science B.V., Molenwerf 1, P.O. Box 211 , 1000 AE Am maling notice - Central and South America only. Periodicals postage paid at Jamaica, NY 11431. USA POSTMASTERS: Send address changes to Chemical Physics Letters, Publications Expediting, Inc., 200 Meacham Avenue, Elmont, NY 11003 . Airfreight and mailing in the USA by Publication Expediting. 


\title{
Electron-ion recombination rate coefficient measurements in a flowing afterglow plasma
}

\author{
Theodosia Gougousi a , Michael F. Golde ${ }^{\mathrm{b}}$, Rainer Johnsen ${ }^{\mathrm{a}}$ \\ a Department of Physics and Astronomy, University of Pittshurgh, Pittsburgh. PA 15260, USA \\ ${ }^{\circ}$ Department of Chemisrry, University of Pittshurgh, Pittshurgh, PA 15260, USA
}

Received 22 November 1996

\begin{abstract}
The flowing-afterglow technique in conjunction with computer modeling of the flowing plasma has been used to determine accurate dissociative-recombination rate coefficients $\alpha$ for the ions $\mathrm{O}_{2}^{+}, \mathrm{HCO}^{+}, \mathrm{CH}_{5}^{+}, \mathrm{C}_{2} \mathrm{H}_{5}^{+}, \mathrm{H}_{3} \mathrm{O}^{+}, \mathrm{CO}_{2}^{+}$, $\mathrm{HCO}_{2}^{+}, \mathrm{HN}_{2} \mathrm{O}^{+}$, and $\mathrm{N}_{2} \mathrm{O}^{+}$at $295 \mathrm{~K}$. We find that the simple form of data analysis that was employed in earlier experiments was adequate and we largely confirm earlier results. In the case of $\mathrm{HCO}^{+}$ions, published coefficients range from $1.1 \times 10^{-7}$ to $2.8 \times 10^{-7} \mathrm{~cm}^{3} / \mathrm{s}$, while our measurements give a value of $1.9 \times 10^{-7} \mathrm{~cm}^{3} / \mathrm{s}$.
\end{abstract}

\section{Introduction}

Rate coefficients for dissociative recombination (DR) of positive molecular ions with electrons are often needed to construct models of cold, weakly ionized plasmas, e.g. terrestrial and planetary ionospheres [1] and interstellar gas clouds [2,3]. Many ions have been studied subsequent to the work of Biondi at al. who used the stationary afterglow technique [4-10]. More recently other techniques, especially flowing afterglows [11-18], but also merged beams $[19,20]$, and ion storage rings [21] have become important tools for such work. The chemical versatility of flowing afterglows has made this technique particularly productive, but a rigorous analysis of the data obtained by this method is a rather difficult task. In this article we present measurements of the recombination coefficients for several polyatomic ions obtained using a flowing afterglow/ Langmuir probe (FALP) apparatus. In part, the present study was motivated by the recent finding $[15,22]$ that the de-ionization of $\mathrm{H}_{3}^{+}$and $\mathrm{D}_{3}^{+}$afterglow plasmas deviates significantly from the simple behavior that is expected for binary recombination of a plasma containing a single ion species. The commonly used approximate methods of deducing recombination rates from graphs of the reciprocal electron density versus time or position tend to mask deviations from a simple recombination decay, and one can never be sure that the inferred recombination coefficients are truly constant during the afterglow. We have sought to improve this situation by developing better approximations for the data analysis which would reveal subtle deviations from a simple recombination decay.

\section{Experimental}

Our flowing afterglow technique [22] and the use of Langmuir probes for electron density measurements [23] have been described in detail elsewhere and will only be summarized here. A microwave 
discharge in helium is used to generate helium metastable atoms, $\mathrm{He}^{*}$. which further downstream ionize argon by Penning ionization. In this work, several of the desired ion species were formed by charge transfer from $\mathrm{Ar}^{+}$.

$\mathrm{Ar}^{+}+\mathrm{XY} \rightarrow \mathrm{XY}^{+}+\mathrm{Ar}$

where $\mathrm{XY}$ is $\mathrm{O}_{2}, \mathrm{CO}_{2}$, or $\mathrm{N}_{2} \mathrm{O}$. To make $\mathrm{C}_{2} \mathrm{H}_{5}^{+}$ ions, $\mathrm{CH}_{+}$was added to the afterglow leading to the reactions

$\mathrm{Ar}^{+}+\mathrm{CH}_{4} \rightarrow \mathrm{CH}_{3}^{+}+\mathrm{H}+\mathrm{Ar}$

$\mathrm{CH}_{3}^{+}+\mathrm{CH}_{4} \rightarrow \mathrm{C}_{2} \mathrm{H}_{5}^{+}+\mathrm{H}_{2}$.

Protonated molecules were produced by first making $\mathrm{H}_{3}^{+}$and subsequently transferring the proton to the molecule under study, i.e..

$\mathrm{Ar}^{+}+\mathrm{H}_{2} \rightarrow \mathrm{ArH}^{+}+\mathrm{H}$

$\mathrm{ArH}^{+}+\mathrm{H}_{2} \rightarrow \mathrm{H}_{3}^{+}+\mathrm{Ar}$

$\mathrm{H}_{3}^{+}+\mathrm{XY} \rightarrow \mathrm{HXY}^{+}+\mathrm{H}_{2}$

where $\mathrm{XY}$ is $\mathrm{CH}_{4}, \mathrm{CO}_{2}, \mathrm{~N}_{2} \mathrm{O}, \mathrm{CO}$, and $\mathrm{H}_{2} \mathrm{O}$. The quadrupole mass spectrometer at the downstream end of the tube was used to monitor the ion composition of the plasma and to ascertain that no significant impurity ions were present.

The movable Langmuir probe measured the electron density as a function of distance $z$. Under typical experimental conditions the electron densities in the upstream region of the flow tube were of the order of $5 \times 10^{10} \mathrm{~cm}^{-3}$, the flow tube pressure was 0.9 Torr. and the central velocity was $\sim 5500 \mathrm{~cm} / \mathrm{s}$.

\subsection{Data analysis}

The usual practice of deducing recombination coefficients from the slopes of the inverse electron density versus distance $\mathrm{z}$ plots is justified only if ambipolar diffusion in radial and axial directions can be safely ignored. The on-axis electron density then follows approximately the equation

$\frac{1}{n_{i}(z)}=\frac{1}{n_{c}(z=0)}+a \frac{z}{v}$.

where $v$ is an 'effective flow velocity' whose precise relation to the central flow velocity does not seem to be well defined. While it is true that the initial slope of a graph of Eq. (7) using experimental values for $n_{\mathrm{e}}$ often yields good values for the recombination coefficient, the problem is that further downstream the transition from a recombination-controlled to a diffusion-controlled afterglow leads to a gradual increase in the slope. In the absence of a better method of analysis, it is difficult to distinguish this effect from an actual change of the apparent recombination coefficient which may be present. Such changes may result from changes in the ion composition, quenching of vibrationally excited ions, or contributions of electron-stabilized recombination.

We have developed an accurate numerical model of the afterglow processes [22] that includes the ion chemistry and recombination. mixing of reagent gases, diffusion and transport of all species in both axial and radial directions in a flow with a parabolic velocity profile. In practice, however, the calculation time was found to be extremely long for routine deduction of recombination coefficients, and the model was used mainly to validate a simpler, approximate method of analysis.

In the approximate solution of the electron continuity equation the gas flow velocity is taken to be radially independent and the radial variation of the electron density is approximated by the fundamental diffusion mode in a cylinder. With these simplifications the continuity equation for the on axis electron density is of the form

$$
\frac{\partial n_{\mathrm{e}}(r=0)}{\partial z}=\frac{1}{v_{0}}\left[-\alpha n_{\mathrm{c}}^{2}+D_{\mathrm{a}}\left(\frac{\partial^{2} n_{\mathrm{e}}}{\partial z^{2}}-\frac{n_{\mathrm{e}}}{\Lambda^{2}}\right)\right] \text {, }
$$

where $A=R / 2.405$ is the fundamental diffusion length for a cylinder of diameter $R, D_{a}$ is the ambipolar diffusion coefficient and $v_{0}$ is the central flow velocity. A fourth-order polynomial leastsquares fit to the measured $z$-dependence of $1 / n_{\mathrm{c}}$ is inserted into Eq. (8), the needed derivatives are obtained analytically, and the equation is then solved for $\alpha(z)$. If the resulting $\alpha(z)$ is independent of $z$, then it can be concluded that a single, constant recombination coefficient prevails during the afterglow. This approximate method of data analysis was tested by creating computer-simulated data using the accurate numerical model and then analyzing them using the approximate method. The results confirmed 
that the approximate method is entirely satisfactory for analyzing experimental data.

Ambipolar diffusion coefficients for the different species are needed as input parameters for Eq. (8). For most ions they were calculated from the known mobilities [24-26] in argon and helium using the Einstein formula relating the diffusion coefficients to the mobilities. In cases where the mobilities in argon were not known the Langevin formula [27] was used to obtain an estimate. The central velocity $v_{0}$ was calculated from the known gas flow rate and the total pressure.

\section{Results and discussion}

The recombination coefficients were measured for the ion species listed in Table 1. Before data were recorded, the mass spectrum was taken to verify that the desired ion species indeed dominated the plasma. As a test case for the technique and the data analysis the recombination coefficient of $\mathrm{O}_{2}^{+}$ions was measured. A value of $(1.9 \pm 0.2) \times 10^{-7} \mathrm{~cm}^{3} / \mathrm{s}$ was obtained, in good agreement with the generally accepted value of $(2.0 \pm 0.2) \times 10^{-7} \mathrm{~cm}^{3} / \mathrm{s}$. Fig. I shows an example of the electron-density decay curve

Table 1

Dissociative recombination coefficients for polyatomic ions measured using a flowing afterglow/Langmuir probe apparatus. Coefficients measured in carlier experiments are also given

\begin{tabular}{|c|c|c|c|c|}
\hline \multirow[t]{2}{*}{ Species } & \multirow[t]{2}{*}{ Present work $\alpha\left(10^{7} \mathrm{~cm}^{3} / \mathrm{s}\right)$} & \multicolumn{3}{|c|}{ Previously reported values } \\
\hline & & $\alpha\left(10^{7} \mathrm{~cm}^{3} / \mathrm{s}\right)$ & Reference & Method" \\
\hline $\mathrm{O}_{2}^{+}$ & $1.9 \pm 0.2$ & $\begin{array}{l}1.95 \\
2.20 \\
2.30 \\
1.95 \\
1.90 \\
2.00\end{array}$ & $\begin{array}{l}\text { Mehr [4] } \\
\text { Kasner [5] } \\
\text { Mul [19] } \\
\text { Alge [11]] } \\
\text { Walls [28] } \\
\text { Spane] [13] }\end{array}$ & $\begin{array}{l}\text { SA } \\
\text { SA } \\
\text { MB } \\
\text { FALP } \\
\text { IT } \\
\text { FALP }\end{array}$ \\
\hline $\mathrm{HCO}$ & $1.9 \pm 0.3$ & $\begin{array}{l}2.0 \\
1.1 \\
2.4 \\
2.8 \\
2.2 \\
1.5\end{array}$ & $\begin{array}{l}\text { Leu [8] } \\
\text { Adams [17] } \\
\text { Ganguli [10] } \\
\text { Amano [29] } \\
\text { Rowe [14] } \\
\text { Smith [15] }\end{array}$ & $\begin{array}{l}\text { SA } \\
\text { FALP } \\
\text { SA } \\
\text { IR } \\
\text { FALP } \\
\text { FALP }\end{array}$ \\
\hline $\mathrm{CO}_{2}$ & $3.5 \pm 0.5$ & $\begin{array}{l}3.8 \\
4.0 \\
3.1\end{array}$ & $\begin{array}{l}\text { Weller [6] } \\
\text { Gutcheck }[30] \\
\text { Geoghegan }[16]\end{array}$ & $\begin{array}{l}\text { SA } \\
\text { SA } \\
\text { FALP }\end{array}$ \\
\hline $\mathrm{N}_{2} \mathrm{O}^{+}$ & $3.6 \pm 0.6$ & & & \\
\hline $\mathrm{HCO}_{2}$ & $4.6 \pm 0.7$ & 3.4 & Adams [12] & FALP \\
\hline $\mathrm{HN}_{2} \mathrm{O}^{+}$ & $4.5 \pm 0.7$ & 4.2 & Adams [12] & FALP \\
\hline $\mathrm{H}_{3} \mathrm{O}^{+}$ & $8.0 \pm 1.5$ & $\begin{array}{r}10.0 \\
3.4 \\
13.0 \\
20.0\end{array}$ & $\begin{array}{l}\text { Herd }[18] \\
\text { Mul }[20] \\
\text { Leu [9] } \\
\text { Heppner }[31]\end{array}$ & $\begin{array}{l}\text { FALP } \\
\text { MB } \\
\text { SA } \\
\text { IT }\end{array}$ \\
\hline $\mathrm{CH}_{5}^{\prime}$ & $9.0 \pm 2.0$ & $\begin{array}{l}11.0 \\
14.0\end{array}$ & $\begin{array}{l}\text { Adams [17] } \\
\text { Smith [15] }\end{array}$ & $\begin{array}{l}\text { FALP } \\
\text { FALP }\end{array}$ \\
\hline $\mathrm{C}_{2} \mathrm{H}_{5}^{+}$ & $9.0 \pm 2.0$ & 7.4 & Adams [12] & FALP \\
\hline
\end{tabular}

SA: Stationary afterglow. FALP: Flowing afterglow/Langmuir probe. IR: Infrared absorption. IT: Ion trap. MB: Merged beam. 


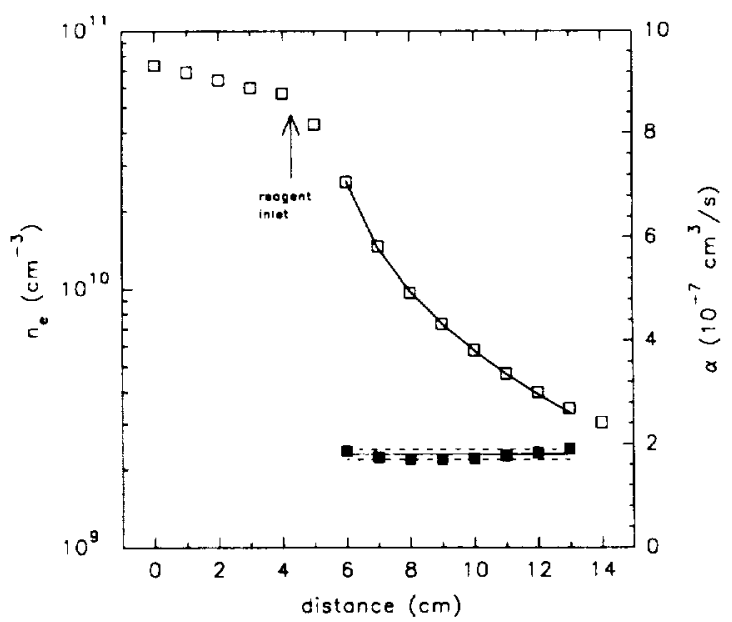

Fig. 1. Values of $\alpha(z)$ (filled squares, right-hand ordinate) from measured $n_{e}(z)$ data (open circles, left-hand ordinate) for an $\mathrm{O}_{2}^{+}$ plasma. The solid line through the $n_{e}(z)$ data represents a fourthorder polynomial fit. The solid line through the $\alpha(z)$ values represents the average, while the dashed lines indicate the one standard deviation interval.

and the deduced $\alpha(z)$ for $\mathrm{O}_{2}^{+}$ions. As was expected, $\alpha(z)$ remains constant over a factor of ten in electron density, supporting the conclusion that deionization occurs by binary recombination of a single ion species. Data of equal quality (see examples in Fig. 2 and Fig. 3) were obtained for most of the other ions in Table 1 . As a rule, the $\alpha(z)$ values for all ions were constant within 10 to $15 \%$ from the mean. None of the ions exhibited the strongly anomalous decay that has been observed for $\mathrm{H}_{3}^{+}$ions $[15,22]$.

For most ion species our recombination coefficients agree well with earlier data where such are available. The agreement among various determinations of $\alpha\left(\mathrm{HCO}^{+}\right)$is poorer than for other ions. The lowest value was reported by Adams et al. [17] at $1.1 \times 10^{-7} \mathrm{~cm}^{3} / \mathrm{s}$ and was revised later by Smith et al. [15] to $1.5 \times 10^{-7} \mathrm{~cm}^{3} / \mathrm{s}$, while the highest value $\left(2.8 \times 10^{-7} \mathrm{~cm}^{3} / \mathrm{s}\right)$ was reported by Amano [29]. With the exception of these two cases the rest of the experiments yielded values near $2.2 \times 10^{-7} \mathrm{~cm}^{3} / \mathrm{s}$ and our result $1.9 \times 10^{-7} \mathrm{~cm}^{3} / \mathrm{s}$ is in good agreement with them.

The state of internal excitation of the various ions is generally not well known. Our data contain no hint that the recombining ion species consisted of mix-

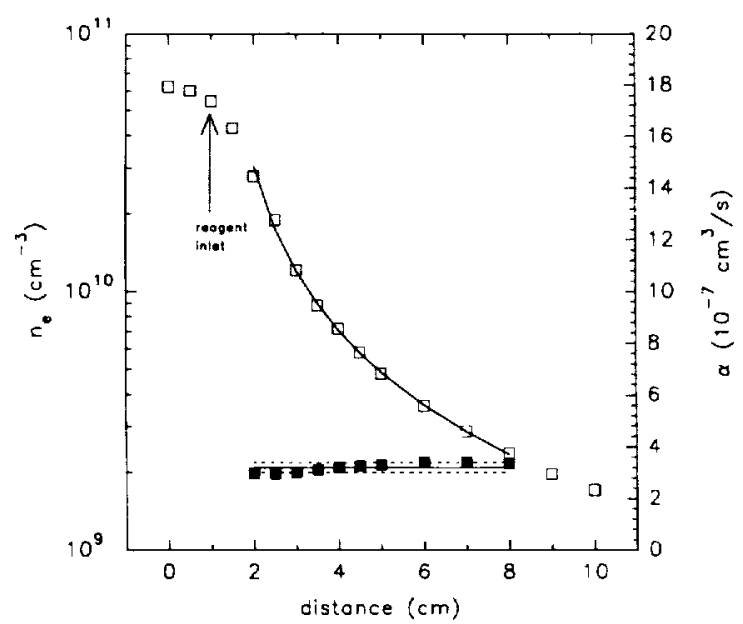

Fig. 2. Values of $\alpha(z)$ (filled squares, right-hand ordinate) from measured $n_{\mathrm{e}}(z)$ data (open circles, left-hand ordinate) for an $\mathrm{CO}_{2}^{+}$ plasma. The solid line through the $n_{\mathrm{e}}(z)$ data represents a fourthorder polynomial fit. The solid line through the $\alpha(z)$ values represents the average, while the dashed lines indicate the one standard deviation interval.

tures of different vibrational states and that these recombined with significantly different recombination coefficients. If this were the case, the finding of a constant recombination coefficient would be rather

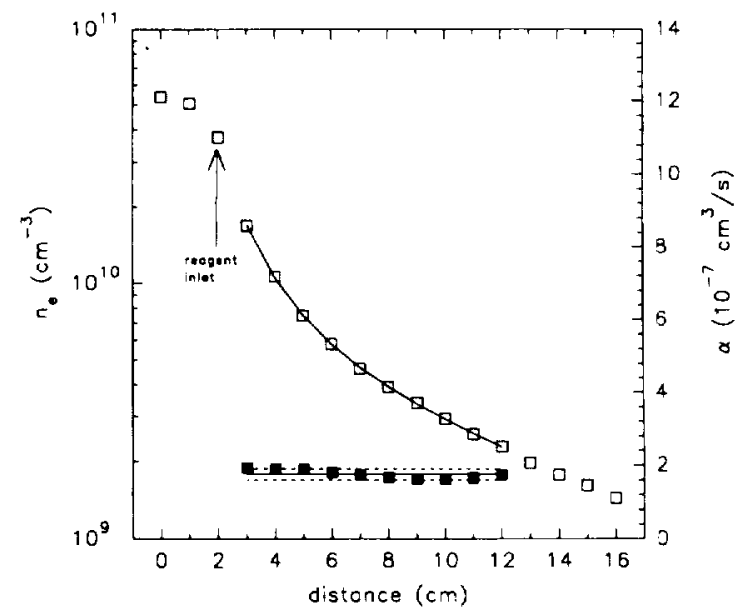

Fig. 3. Values of $\alpha(z)$ (filled squares, right hand side axis) from measured $n_{\mathrm{e}}(z)$ data (open circles, left-hand ordinate) for an $\mathrm{HCO}^{+}$plasma. The solid line through the $n_{\mathrm{e}}(z)$ data represents a fourth-order polynomial fit. The solid line through the $\alpha(z)$ values represents the average, while the dashed lines indicate the one standard deviation interval. 
surprising. Since vibrationally excited ions are often quenched to lower states in collisions with molecular gases, the presence of excited ions might also lead to an apparent dependence of the recombination coefficient on reagent pressure. However, measurements at different reagent concentrations resulted in no more than 10 to $15 \%$ variation of the recombination coefficient indicating that either the ions were in their ground state or that there is little dependence of $\alpha$ on vibrational state.

While our data agree well with many other determinations, it should be noted that most other determinations were made in plasmas of similar pressures and electron density. There is still lack of accurate absolute recombination coefficients (or cross sections) measured under essentially single-collision conditions, such as in merged-beam or ion storage rings.

\section{Acknowledgements}

This work was in part supported by NASA under Grant. No. NAGW 1764. Theodosia Gougousi is grateful to the Andrew Mellon Foundation for providing a predoctoral scholarship.

\section{References}

[1] G.C. Reid, Adv. At. Mol. Phys. 63 (1976) 375.

[2] A. Dalgarno and J.H. Black, Rep. Prog. Phys. 39 (1976) 573.

[3] T.J. Millar, D.J. DeFrees, A.D. McLean and E. Herbst. Astron. Astrophys. 194 (1988) 250.

[4] F.J. Mehr and M.A. Biondi, Phys. Rev. 181 (1969) 264.

[5] W.H. Kasner and M.A. Biondi, Phys. Rev. 174 (1968) 139.

[6] C.S. Weller and M.A. Biondi, Phys. Rev. Lett. 19 (1967) 59.

[7] C.M. Huang, M.A. Biondi, and R. Johnsen. Phys. Rev. A 11 (1975) 901 .
[8] M.T. Leu, M.A. Biondi and R. Johnsen, Phys. Rev. A 8 (1973) 420.

[9] M.T. Leu, M.A. Biondi and R. Johnsen, Phys. Rev. A 7 (1973) 292.

[10] B. Ganguli, M.A. Biondi, R. Johnsen and J.L. Dulaney, Phys. Rev. A 37 (1988) 2543.

[11] E. Alge, N.G. Adams and D. Smith, J. Phys. B 16 (1983) 1433.

[12] N.G. Adams and D. Smith, Chem. Phys. Lett. 144 (1988) 11.

[13] P. Spanel, L. Dittrichova and D. Smith, Int. J. Mass Spectrom. Ion Proc. 129 (1993) 183.

[14] B.R. Rowe, J.C. Gomet, A. Canosa, C. Rebrion and J.B.A. Mitchell, J. Chem. Phys. 96 (1992) 1105.

[15] D. Smith and P. Spanel, Int. J. Mass Spectrom. Ion Proc. 129 (1993) 163.

[16] M. Geoghegan, N.G. Adams and D. Smith, J. Phys. B 24 (1991) 2589.

[17] N.G. Adams, D. Smith, and E. Alge, J. Chem. Phys. 81 (1984) 1778.

[18] C.R. Herd, N.G. Adams and D. Smith, Ap. J. 349 (1990) 388.

[19] P.M. Mul, and J. Wm. McGowan J. Phys. B 12 (1979) 1591

[20] P.M. Mul, J. Wm. McGowan, P. Defrance and J.B.A. Mitchell, J. Phys. B. 16 (1983) 3099.

[21] M. Larsson, Int. J. Mass Spectrom. Ion Proc. 149/150 (1995) 403.

[22] T. Gougousi, R. Johnsen and M.F. Golde, Int. J. Mass Spectrom. Ion Proc. 149/150 (1995) 131.

[23] R. Johnsen, E.V. Shun ko, T. Gougousi and M.F. Golde, Phys. Rev. E 50 (1994) 3994.

[24] H.W. Ellis, R.Y. Pai, E.W. McDaniel, E.A. Mason and L.A. Viehland, At. Data Nucl. Tables 17 (1976) 177.

[25] H.W. Ellis, E.W. McDaniel, D.L. Albritton, L.A. Viehland, S.L. Lin and E.A. Mason, At. Data Nucl. Tables 22 (1978) 179.

[26] H.W. Ellis, M.G. Thackston, E.W. McDaniel and E.A. Mason, At. Data Nucl. Tables 31 (1984) 113.

[27] E.W. McDaniel, J.B.A. Mitchell and M.E. Rudd. Atomic Collisions: Heavy Particle Projectiles, (Willey, 1993) p. 498.

[28] F.L. Walls and G.H. Dunn, J. Geophys. Res. 79 (1974) 1911 .

[29] T. Amano, J. Chem. Phys. 92 (1990) 6492.

[30] R.A. Gutcheck and E.C. Zipf, J. Geophgys. Res. 78 (1973) 5429.

[31] R.A. Heppner, F.L. Walls, W.T. Armstrong and G.H. Dunn, Phys. Rev. A 13 (1976) 1000. 

Orders, claims, and product enquiries: please contact the Customer Support Department at the Regional Sales Office nearest to you:

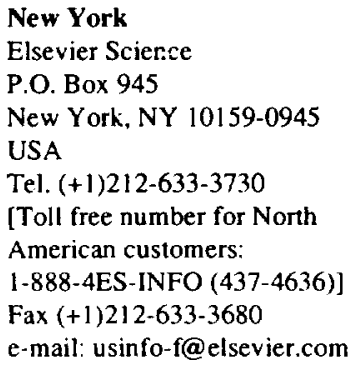

Tokyo
Elsevier Science
9-15 Higashi-Azabu l-chome
Minato-ku, Tokyo 106
Japan
Tel. (+81)3-5561-5033
Fax (+81)3-5561-5047
e-mail: kyf04035@niftyserve.or.jp

\author{
Singapore \\ Elsevier Science \\ No. 1 Temasek Avenue \\ \#17-01 Millenia Tower \\ Singapore 039192 \\ Tel. $(+65) 434-3727$ \\ Fax (+65)337-2230 \\ e-mail: asiainfo@elsevier.com.sg
}

Advertising information: Advertising orders and enquiries may be sent to: International: Elsevier Science, Advertising Department, The Boulevard, Langford Lane, Kidlington, Oxford OX5 1GB, UK, Tel. (+44)(0)1865 843565, Fax $(+44)(0) 1865$ 843976. USA and Canada: Weston Media Associates, Daniel Lipner, P.O. Box 1110, Greens Farms, CT 06436-1110, USA, Tel. $(+1)(203) 261-2500$, Fax $(+1)(203) 261-0101$. Japan: Elsevier Science Japan, Marketing Services, 1-9-15 Higashi-Azabu, Minato-ku, Tokyo 106, Japan, Tel. (+81)3-55615033, Fax (+81)3-5561-5047.

Electronic manuscripts: Electronic manuscripts have the advantage that there is no need for the rekeying of text, thereby avoiding the possibility of introducing errors and resulting in reliable and fast publication.

Your disk plus three, final and exactly matching printed versions should be submitted together. Double density (DD) or high density (HD) diskettes ( $31 / 2$ or $5^{1 / 4}$ inch) are acceptable. It is important that the file saved is in the native format of the wordprocessor program used. Label the disk with the name of the computer and wordprocessing package used, your name, and the name of the file on the disk. Further information may be obtained from the Publisher.

Authors in Japan please note: Upon request, Elsevier Science Japan will provide authors with a list of people who can check and improve the English of their paper (before submission). Please contact our Tokyo office: Elsevier Science Japan, 1-9-15 Higashi-Azabu, Minato-ku, Tokyo 106; Tel. (03)-5561-5032; Fax (03)-55615045.

Chemical Physics Letters has no page charges.

For a full and complete Instnuctions to Authors, please refer to Chemical Physics Letters, Vol. 264, No. 6, pp. 700-701. The instructions can aiso be found on the World Wide Web: access under http://www.elsevier.nl or http://www.elsevier.com.

(-) The paper used in this publication meets the requirements of ANSI/NISO Z39.48-1992 (Permanence of Paper) 
